\title{
Editorial
}

\section{Burden of metabolic diseases in Indonesia: an even more critical issue during COVID-19 pandemic}

\author{
Dicky Levenus Tahapary, Pradana Soewondo
}

The increasing prevalence of obesity in Indonesia has reached an alarming rate. ${ }^{1-4}$ In parallel with the increasing prevalence of obesity and central obesity reaching to one third of Indonesian adult population in $2018,{ }^{2}$ the prevalence of diabetes mellitus (DM) has also almost doubled in the past 10 years reaching more than $10 \%$ of adult population. ${ }^{2,5}$ It is also important to note that the prevalence of prediabetes, a group of people with a higher risk to develop DM in the future, as well as dyslipidemia, has also reached more than one third of adult Indonesian population. ${ }^{2}$ These increasing burdens present a new challenge to enact responsive changes in policy and research. ${ }^{6}$

The increasing prevalence of obesity and central obesity has been shown to be associated with the increased risk of not only type 2 DM (T2DM), but also hypertension and dyslipidemia, of which insulin resistance is the main pathogenesis. A recent systematic review reported that the prevalence of overweight/obesity has increased over the past two decades in Indonesian population regardless of age. ${ }^{3}$ One of the main drivers of increased risk of obesity is urbanization, ${ }^{7}$ which is related not only with people moving from rural to urban area and then adopting urban lifestyle, but also adoption of a more urbanized lifestyle among people living in rural area.?

Obesity has been reported higher in those living in urban areas than rural areas. ${ }^{3}$ In line with this, we have previously reported that living in urban area is associated with a yearly increase in body mass index (BMI) and waist circumference, which then lead to an insulin resistance and increased cardiometabolic risk factors. ${ }^{8}$ However, it is also important to note that our previous study has also shown that the prevalence of obesity, as well as DM, hypertension, and dyslipidemia, has also increased in Indonesia leading to a comparable prevalence with those in developed countries. ${ }^{9}$ Moreover, we also observed an increasing prevalence of obesity and metabolic diseases in rural
Check for updates

areas, ${ }^{10,11}$ confirming a previous report that the main driver of increasing worldwide problem of obesity is the increase of BMI among people living in rural area. ${ }^{7}$ These findings necessitate that priorities to tackle surging prevalence of metabolic diseases should be implemented not only in urban areas, but also in rural areas of Indonesia.

This increasing burden of metabolic diseases in Indonesia will in turn lead to an exponential increase of cardiovascular diseases. Thus, an early detection and prompt intervention is a must. Early detection of obesity and central obesity only requires simple anthropometric measurements, which are BMI and waist circumference, respectively. Therefore, these measurements should generally be applied in all primary care settings. However, defining the cut-off point use to define central obesity for Indonesian population is quite tricky as Indonesia is a multiethnic country. ${ }^{11}$ We have previously shown, indeed, different ethnic groups might have different waist circumference cut-off points for defining central obesity. ${ }^{11}$ Inappropriate cut-offs points used in a wide-nation population might underdiagnose or over-diagnose obesity and its associated future complications. Several formulas to define a higher risk of people among those of obesity, have also been developed to predict the presence or development of metabolic complications of obesity. ${ }^{12}$ However, future studies are needed to clearly define obesity for Indonesian population as well as developing tools to predict the development of future cardiometabolic complications. Thus, an aggressive intervention can be performed in those high-risk subjects.

Aside from obesity, increasing number of people with prediabetes also necessitates urgent intervention, as this group of people is at a higher risk to develop T2DM and its complication in the future. Recent study reported that the prevalence of prediabetes in rural and urban Indonesia has reached $44.8 \%$ and $34.9 \%$ respectively. ${ }^{13}$ Interestingly, the risk of prediabetes 
has already increased starting from the age of $30 .{ }^{13}$ In line with this finding, around one-quarter of people with DM in Indonesia are less than 45 years old, ${ }^{2}$ or commonly grouped as an early onset DM, which is associated with worse outcomes. At the community level, it is urgently needed to start the screening for metabolic diseases in Indonesia at an earlier age. The identification of high-risk group of people at its earliest phase and a prompt intervention could potentially prevent the development of metabolic diseases and its complications. At the community level, the integrated post for non-communicable diseases should play an important role in terms of early identification and referral to an adjacent primary health care center.

The increasing prevalence of metabolic diseases in Indonesia has put a great burden to Indonesian health system, as metabolic diseases and their complications are associated with high morbidity and mortality, and their management is associated with a high cost. It is also important to note that recent studies have shown that the presence of metabolic diseases is associated not only with increased risk of cardiovascular mortality, but also with worse outcome in terms of infectious diseases, such as tuberculosis and recently coronavirus disease 2019 (COVID-19). The relation between metabolic diseases and COVID-19 can be both ways. The COVID-19 pandemic has limited access to care for most people with metabolic diseases that potentially increase the risk for acute complications. However, the COVID-19 has accelerated the transition of medical care on metabolic diseases from traditional offline clinic into a telemedicine approach. Indeed, the area of metabolic and endocrine diseases are the earliest adopting this transition. The application of telehealth in Indonesia with its diverse geographical access is a promising approach but not without challenges. The development of mobile applications to help the management of metabolic diseases has increased. However, its usage in clinical practice is still limited, in some part due to the still relatively low digital literacy among patients, as well as some physicians. In relation to digital health, the development of artificial intelligence is also promising, as it can potentially help to reduce the frequency and shorten the duration of clinic visit during the COVID-19 pandemic.

On the other hand, the presence of metabolic diseases has been reported with worse outcomes of COVID-19, of which obesity and DM have been consistently reported. ${ }^{14}$ In addition, hyperglycemia, independent of DM status, is also associated with worse outcome in COVID-19. Despite having a younger population in comparison to developed countries, the high prevalence of metabolic diseases in Indonesia, including those in younger age, closer intergenerational contact, and limited healthcare capacity, can potentially increase the number of severe COVID-19 cases and mortality in Indonesia. ${ }^{15}$ To this end, there is an urgency to prevent COVID-19 spread, especially among the high risk group with metabolic diseases. While waiting for the efficacy of vaccine, handwashing, wearing a mask, physical distancing, as well as increasing coverage of test and contact tracing are of paramount importance.

In summary, the increasing burden of metabolic diseases in Indonesia needs a comprehensive management, which should focus on a prevention and early detection starting from the community level. The pandemic of COVID-19 has put those people with metabolic diseases at an increased risk of severe cases and mortality necessitating the importance of COVID-19 prevention in this high-risk group. While this pandemic has an enormous toll on health and other aspects of life, there is a silver lining which has driven the disruption in the care of metabolic diseases by forcing a faster adoption of digital health.

From Medical Journal of Indonesia; Department of Internal Medicine, Faculty of Medicine, Universitas Indonesia, Cipto Mangunkusumo Hospital, Jakarta, Indonesia; Metabolic, Cardiovascular and Aging Cluster, The Indonesian Medical Education and Research Institute, Faculty of Medicine, Universitas Indonesia, Jakarta, Indonesia pISSN: 0853-1773 • elSSN: 2252-8083 https://doi.org/10.13181/mji.ed.205208

Med J Indones. 2020;29:347-9

Corresponding author:

Dicky Levenus Tahapary

E-mail: dicky.tahapary@ui.ac.id

\section{REFERENCES}

1. Harbuwono DS, Pramono LA, Yunir E, Subekti I. Obesity and central obesity in indonesia: evidence from a national health survey. Med J Indones. 2018;27(2):114-20.

2. Ministry of Health of The Republic of Indonesia. Basic Health Research (RISKESDAS) 2018. Ministry of Health of the Republic of Indonesia: National Institute of Health Research and Development; 2018. Indonesian.

3. Oddo VM, Maehara M, Rah JH. Overweight in Indonesia: an observational study of trends and risk factors among adults and children. BMJ Open. 2019;9:e031198.

4. Rachmi CN, Li M, Alison Baur L. Overweight and obesity in Indonesia: prevalence and risk factors-a literature review. Public Health. 2017;147:20-9.

5. Soewondo P, Ferrario A, Tahapary DL. Challenges in diabetes management in Indonesia: a literature review. Global Health. 
2013;9:63

6. Mboi N, Murty Surbakti I, Trihandini I, Elyazar I, Houston Smith $\mathrm{K}$, Bahjuri Ali $\mathrm{P}$, et al. On the road to universal health care in Indonesia, 1990-2016: a systematic analysis for the Global Burden of Disease Study 2016. Lancet. 2018;392(10147):581-91.

7. Bixby H, Bentham J, Zhou B, Di Cesare M, Paciorek CJ, Bennett $\mathrm{JE}$, et al. Rising rural body-mass index is the main driver of the global obesity epidemic in adults. Nature. 2019;569(7755):260-4.

8. Tahapary DL, de Ruiter K, Kurniawan F, Djuardi $\mathrm{Y}$, Wang $\mathrm{Y}$, Nurdin SME, et al. Impact of rural-urban environment on metabolic profile and response to a 5-day high-fat diet. Sci Rep. 2018;8(1):8149.

9. Sigit FS, Tahapary DL, Trompet S, Sartono E, Willems van Dijk $\mathrm{K}$, Rosendaal FR, et al. The prevalence of metabolic syndrome and its association with body fat distribution in middle-aged individuals from Indonesia and the Netherlands: a crosssectional analysis of two population-based studies. Diabetol Metab Syndr. 2020;12:2.

10. Waspadji S, Soewondo P, Subekti I, Soebardi S, Harbuwono DS, Pramono LA, et al. Ende diabetes study: diabetes and its characteristics in rural area of East Nusa Tenggara. Med $J$ Indones. 2013;22(1):30-8.
11. Tahapary DL, Harbuwono DS, Yunir E, Soewondo P. Diagnosing metabolic syndrome in a multi-ethnic country: is an ethnicspecific cut-off point of waist circumference needed? Nutr Diabetes. 2020;10(19).

12. Nusrianto R, Ayundini G, Kristanti M, Astrella C, Amalina N, Muhadi, et al. Visceral adiposity index and lipid accumulation product as a predictor of type 2 diabetes mellitus: the Bogor cohort study of non-communicable diseases risk factors. Diabetes Res Clin Pract. 2019;155:107798.

13. Dany F, Dewi RM, Tjandrarini DH, Pradono J, Delima D, Sariadji $\mathrm{K}$, et al. Urban-rural distinction of potential determinants for prediabetes in Indonesian population aged $\geq 15$ years: a crosssectional analysis of Indonesian Basic Health Research 2018 among normoglycemic and prediabetic individuals. BMC Public Health. 2020;20(1):1509.

14. Tamara A, Tahapary DL. Obesity as a predictor for a poor prognosis of COVID-19: a systematic review. Diabetes Metab Syndr. 2020;14(4):655-9.

15. Walker PGT, Whittaker C, Watson OJ, Baguelin M, Winskill $P$, Hamlet A, et al. The impact of COVID-19 and strategies for mitigation and suppression in low- and middle-income countries. Science. 2020;369(6502):413-22. 